Accepted (peer-reviewed) version of article It is authorized for self-archiving after an embargo period of 12 months. Formatted by the author to enhance readability. 
Published in 2012 as Behavioral Sciences and the Law, 30(2), 154-166.

\title{
Prevalence of ADHD and Its Subtypes in Male and Female Adult Prison Inmates
}

\author{
Brian S. Cahill, M.A.†, Frederick L. Coolidge, Ph.D.*,

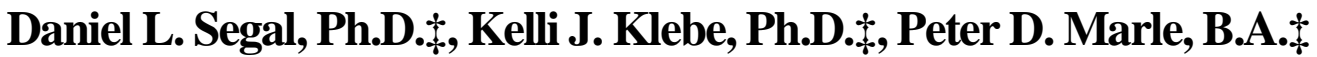 \\ and Karenleigh A. Overmann, B.A. $\$$
}

\begin{abstract}
There are few published studies of attention-deficit/hyperactivity disorder (ADHD) in adult inmates, and even fewer studies that have considered $A D H D$ in adult inmates by gender. The present study examined the prevalence of $A D H D$, its subtypes, and associated psychological and neuropsychological comorbidity as a function of gender in a sample of 3,962 inmates $(3,439$ men and 523 women; mean age $=33.6$ years, range 17-73) who had completed the 250-item, self-report, Diagnostic and Statistical Manual of Mental Disorders, $4^{\text {th }}$ edition (Text Revision) (DSM-IV-TR)-aligned Coolidge Correctional Inventory (CCI). The overall ADHD prevalence rate found was $10.5 \%$, which is substantially higher than the rate among adults in the general population (2-5\%). The female inmate ADHD prevalence rate (15.1\%) was higher than the male inmate ADHD rate (9.8\%), consistent with some previous studies. The most prevalent $A D H D$ subtype for both genders was the hyperactive-impulsive subtype. The combined and inattentive ADHD subtypes had higher levels of comorbid psychopathology than the hyperactive-impulsive ADHD subtype. As the presence of ADHD and associated gender differentials may impact the success of rehabilitation and educative programs with inmates, the assessment of ADHD and comorbid psychopathology should be a priority in initial inmate screening and evaluation.
\end{abstract}

There are few published studies of attention-deficit/hyperactivity disorder (ADHD) in adult inmates that have considered ADHD by gender, and no studies to date have based their prevalence estimates on the verbatim ADHD criteria in the Diagnostic and Statistical Manual of Mental Disorders (DSM-III-R, American Psychiatric Association, 1987; DSM-IV, American Psychiatric Association, 1994; DSM-IV-TR, American Psychiatric Association, 2000). In childhood, ADHD prevalence rate estimates vary from about $4 \%$ to $12 \%$ of 6 - to 12 -year-old children in non-referred community and primary care pediatric samples, whereas the rate approaches $50 \%$ in psychiatrically referred populations, with the prevalence rate for boys being two to four times greater than that of girls (e.g., Barzman, Fieler, \& Sallee, 2004). Wasserstein (2005) stated that ADHD was once thought to dissipate as children matured, but current data suggest that the features of ADHD undergo changes while still remaining clinically significant for many of the adults who had ADHD as children. Specifically, it is estimated that 30-65\% of children with ADHD continue to display clinically significant symptoms as adults (e.g., McGough \& Barkley, 2004; Span, Earleywine, \& Strybel 2002), increasing the risk of their developing behaviors in adulthood that elevate the likelihood of incarceration. The overall prevalence of ADHD in adults is estimated at 2-5\% (e.g., Barkley \& Murphy, 1998, who also noted that DSM criteria for ADHD were based on

\footnotetext{
* Address correspondence to: Frederick L. Coolidge, Ph.D., Department of Psychology, University of Colorado, 1420 Austin Bluffs Parkway, Colorado Springs, CO 80918, U.S.A. E-mail: fcoolidg@uccs.edu. † Psychology Department, Florida International University, Miami. ‡ Department of Psychology, University of Colorado, Colorado Springs. This article was based on a Master's thesis by Brian S. Cahill.
} 
samples that were largely adult men). In the largest meta-analysis to date of 102 studies that included 171,756 subjects (children and adults), Polanczyk, Silva de Lima, Horta, Biederman and Rohde (2007) found a worldwide prevalence rate of ADHD of 5.3\%.

With respect to a diagnosis of subtypes of ADHD in childhood (i.e., inattentive, hyperactive-impulsive, and combined types), the most common subtype appears to be the inattentive type (50\%), followed by the combined type (30\%), and lastly the hyperactive-impulsive type [20\%; Graetz, Sawyer, Hazell, Arney, \& Baghurst, 2001 (this meta-analysis excluded gender because fewer than half of the included studies considered it); Wolraich, Hannah, Pinnock, Baumgaertel, \& Brown, 1996 (this study noted that some studies have found a higher proportion of females in the inattentive types)]. Prevalence rates of ADHD in both juvenile and adult prison populations appear to be greater than that of the general population. In a study of 1,829 juveniles in temporary detention, $17 \%$ of males and $21 \%$ of females were diagnosed with ADHD (Teplin, Abram, McClelland, Dulcan, \& Mericle, 2002). The higher rates of ADHD seen in juvenile delinquents appear to exist cross-culturally as well. For example, in a sample of incarcerated juvenile boys in the Netherlands, 8\% met the criteria for ADHD (Vreugdenhil, Doreleijers, Vermeiren, Wouters, \& Van Den Brink, 2004), in Korea 33\% of incarcerated boys and 52\% of incarcerated girls met the criteria for ADHD (Chae, Jung, \& Noh, 2001), and 45\% of incarcerated young males in Germany met the criteria for ADHD (Rösler et al., 2004). Overall, these studies consistently demonstrate that the elevated rate of ADHD in juvenile prison populations is a worldwide phenomenon. Based on studies in the general population where it appears that ADHD symptoms persist into adulthood for a majority of children with ADHD, elevated rates of ADHD would be expected in adult prison populations.

Eyestone and Howell (1994), in a study of 102 randomly chosen male adult inmates, found a self-reported ADHD prevalence rate of 26\%, although their estimate was not based on strict DSM criteria. In a review of the literature on ADHD in prison populations, Eme (2009) (see also Hurley \& Eme, 2008) estimated that the ADHD rate in adult prison inmates is at least 25\%, although, again, there was no strict adherence to DSM ADHD criteria. Eme also reported that at least two studies have found that the ADHD prevalence rates for adult female inmates meet or exceed those of adult male inmates. Coolidge, Segal, Klebe, Cahill, and Whitcomb (2009) found that the prevalence of ADHD in adult inmates ranged from 3.6\% to 16.3\% (depending on whether the ADHD was assessed dimensionally or categorically, or both). One strength of the latter study was that they used the 18 diagnostic criteria in DSM-IV-TR for ADHD, although they did not analyze ADHD prevalence as a function of gender or subtype.

\section{ADHD COMORBIDITY}

According to the DSM-IV-TR, approximately half of clinic-referred children with ADHD also have oppositional defiant disorder (ODD) or conduct disorder (CD). Barkley (2005) and Szatmari, Offord, and Boyle (1989) reported that approximately 44\% of those classified with ADHD have at least one other psychiatric disorder, 32\%have two other disorders, and $11 \%$ have at least three other disorders. Executive function (EF) deficits of the frontal lobes (e.g., poor planning, disorganization, disinhibition, decision-making difficulties) have also been suggested to be a comorbid characteristic of ADHD. In their review of 18 studies of EF deficits in ADHD, Pennington and Ozonoff (1996) found that 15 of the studies revealed significant deficits on one or more measures of EF in ADHD children compared with controls. They concluded that children 
with ADHD might have a mix of specific deficits (like an essential EF deficit) and some general deficits (such as a general cognitive inefficiency). Indeed, the finding is so robust that ADHD in childhood is accompanied by EF deficits that Pennington and Ozonoff (1996) have considered EF deficits as the "core deficit" in ADHD. Eme (2009) has also noted that ADHD appears to be comorbid with EF deficits in adult prison inmates.

With regard to the comorbidity rates in ADHD adults, Murphy and Barkley (1996) found in a sample that was $60 \%$ male that ADHD adults had a significantly greater prevalence of oppositional, conduct, and substance-abuse disorders, and greater illegal substance use than control adults. Also, adults with ADHD displayed greater self-reported psychological maladjustment, more driving risks (e.g., speeding violations), and more frequent changes in employment (Murphy \& Barkley, 1996).

\section{ADHD SUBTYPES AND COMORBIDITY}

Comorbidity differences have been found in children between the three subtypes of ADHD and higher rates compared with comparison groups (e.g., Eiraldi, Power, \& Nezu, 1997; Willcutt, Pennington, Chhabildas, Friedman, \& Alexander, 1999), but no study to date has examined comorbidity as a function of ADHD subtype in adults or in prison populations. Willcutt and colleagues (1999) found that hyperactive-impulsive symptoms were more strongly associated with both ODD and CD than inattention symptoms, whereas the inattentive and combined types were associated with higher levels of depression. Eiraldi and colleagues (1997) found that ADHD children with the combined type showed significantly higher levels of ODD and CD than children with the inattentive type and controls, but there were no differences between the combined or inattentive subtypes regarding levels of depression and anxiety. Overall, these studies appear to demonstrate that all three of the subtypes of ADHD in childhood have higher rates of comorbid disorders compared with controls, and the combined type consistently has the highest rates of comorbid disorders of the three subtypes. No studies to date, in either children or adults, have examined the comorbidity of personality disorders with ADHD or its subtypes.

\section{THE CURRENT STUDY}

This study examined the prevalence of ADHD and its subtypes as a function of gender in a large sample of adult prisoners. Comorbidity differences were also examined among the three ADHD subtypes. It was hypothesized that the ADHD prevalence rate in this prison population would be greater than in the general population, and based on studies of juvenile delinquents, it was also hypothesized that the ADHD prevalence rate would be greater for females than for male inmates. Regarding ADHD subtypes, it was hypothesized that the inattentive subtype would be the most common followed by the combined subtype, and the hyperactive-impulsive would be the least common. It was also hypothesized that the ADHD subtype prevalence would not vary as a function of gender. Finally, it was hypothesized that all three ADHD subtypes should have a stronger association with comorbid Axis I syndromes (anxiety, depression, and schizophrenia), Axis II personality disorders, and neuropsychological dysfunction (including EF deficits associated with the frontal lobes) compared with a comparison group of inmates without ADHD. 


\section{METHOD}

\section{Participants}

The initial group of participants comprised 4,872 inmates consecutively admitted to the Colorado Department of Corrections (CDOC) over a period of approximately nine months. The data were collected as part of the standard intake process to the Colorado prison system. The Coolidge Correctional Inventory (CCI) is administered routinely to all inmates upon entry to prison. All data were collected archivally from a database maintained by the CDOC, and all records were anonymous. Each inmate, in approximately a two-hour testing period, completed approximately four intake measures in groups of 20-45 inmates. Of note, these data were previously analyzed in two studies with a different focus than that of the current study (Coolidge et al., 2009; Coolidge, Marle, Van Horn, \& Segal, 2011).

\section{Initial Data CCI Screening Procedure}

Based upon previous research with the Millon Clinical Multiaxial Inventory in prison populations (Retzlaff et al., 2002), the present 4,872 CCI inmate profiles were screened for random responding, excessive denial, and an excessive number of omitted items. Overall, 13\% (657 protocols) were eliminated from further analysis due to random responding. According to the CCI manual (Coolidge, 2004), a score below 120 (greater than 1.8 SD below the normative CATI mean) on the denial-malingering scale is indicative of excessive denying and may be eliminated from analyses. Also, a score on this scale greater than 299 may be indicative of malingering (Coolidge et al., 2000). These cutoff scores resulted in the elimination of an additional $4 \%(n=202)$ of the inmates' protocols. Finally, $1 \%(n=51)$ of the protocols was eliminated from analysis due to failure to answer at least 235 of the 250 CCI items (again according to the CCI manual). Thus, a total of $19 \%$ of the original sample $(n=910)$ was eliminated from further analysis, resulting in a sample of 3,962 valid inmate protocols.

\section{Final Sample Demographics}

The mean age of the participants was 33.6 years ( $S D=9.5$ years), with a range of 17-73 years. The vast majority of the sample were men $(87 \% ; n=3,439)$, and $13 \%$ were women $(n=$ 523). Ethnic background of the participants was $31 \%$ White, $20 \%$ Hispanic, $11 \%$ Black, $1 \%$ American Indian, $1 \%$ Asian, and 36\% of mixed or unknown ethnicity. Approximately $64 \%$ of the sample had at least a high school diploma or high school equivalency (GED). Approximately $72 \%$ of the inmates were incarcerated for the first time (in Colorado), and about 9\% were incarcerated for the third time or more. Approximately 34\% were incarcerated for a crime of violence.

\section{ADHD Sample and Comparison Group Screening Procedures}

A polythetic, categorical approach, suggested in the DSM-IV-TR (2000), was used as the basis for group inclusion. The 18 items in the CCI that address the 18 diagnostic criteria for ADHD in DSM-IV-TR were collapsed into (0) for answers 1 or 2 indicating that the participant is not endorsing the symptom in question, and into (1) for answers 3 or 4 indicating that the participant is endorsing the symptom in question. The nine CCI items that address the nine DSM-IV-TR inattentive criteria and the nine items that address the hyperactive-impulsive symptoms were summed. Those participants who met at least six of the nine inattentive criteria and fewer than six of the hyperactive-impulsive criteria were included in the inattentive group $(n=150)$; those participants who met at least six of the nine hyperactive-impulsive criteria and fewer than six of the inattentive criteria were included in the hyperactive-impulsive group $(n=198)$; and those participants who met 
at least six of the nine inattentive symptoms and at least six of the nine hyperactive-impulsive symptoms were included in the combined group $(n=68)$. The comparison group of inmates without ADHD $(n=411)$ was obtained by randomly sampling approximately $11 \%$ of the remaining sample of inmates $(n=3,546)$ who failed to meet the criteria to be included in one of the three ADHD groups, in order to have a comparison group of approximately the same sample size as the ADHD group.

One-way analysis of variance (ANOVA) was used to establish that there were no differences in age among the three ADHD subtype groups and the comparison group of inmates without $\operatorname{ADHD}[F(3,823)=0.26, p>0.05]$. Two chi-squared analyses were used to establish that there were no differences in gender and ethnicity among the three ADHD subtypes and the comparison group of inmates without $\operatorname{ADHD}\left[\chi^{2}(3, N=827)=3.53, p>0.05 ; \chi^{2}(12, N=827)=\right.$ 11.31, $p>0.05$, respectively]. Thus, the three ADHD groups and the comparison group of inmates without ADHD were comparable on age, gender, and ethnicity.

\section{Measure}

\section{Coolidge Correctional Inventory (Coolidge, 2004)}

The CCI is a 250-item, self-report (and significant other report) measure, designed to assess major DSM-IV-TR Axis I clinical disorders and Axis II personality disorders as well as neuropsychological dysfunction. The CCI was specifically designed to provide a cost-effective measure of both psychological and neuropsychological syndromes in prison populations, to be a DSM-IV-TR criteria-aligned measure, and to allow the differentiation of those inmates who meet DSM-IV-TR criteria for the syndrome from those who do not. The CCI has a total of 33 clinical scales. There are also two validity scales, one a three-item scale measuring random responding (in which it is highly unlikely there would be any answer other than strongly false, e.g., "I played quarterback for the Denver Broncos") and the other a 97-item denial-malingering scale (in which excessively low scores are indicative of denial and excessively high scores are indicative of malingering). Each scale's items are answered on a four-point Likert-type scale ranging from 1 (strongly false) to 4 (strongly true). In the present study, the following CCI scales were analyzed: 14 personality disorder scales [12 from DSM-IV-TR and two from DSM-III-R (sadistic and selfdefeating)], four DSM-IV-TR Axis I clinical disorder scales (generalized anxiety disorder, major depressive disorder, ADHD, and schizophrenia), a neuropsychological dysfunction scale [NPD; with three subscales assessing memory and attention problems, language dysfunction, and neurosomatic symptoms (symptoms specific to brain dysfunction)], and a scale assessing EF deficits of the frontal lobes (with three subscales measuring decision-making difficulties, poor planning, and a failure to complete tasks despite the general ability to do so). It is important to note that the 18 CCI ADHD items were derived directly from the 18 diagnostic criteria for adults in DSM-IV-TR.

Initial psychometric properties for the CCI were established on a sample of 3,962 adult inmates (Coolidge et al., 2009). In the latter study, the median internal scale reliability for the 14 CCI personality disorder scales was 0.78 (Cronbach's a), the median internal scale reliability for the four Axis I scales was 0.88, and the median internal scale reliability for all 33 CCI scales was 0.79 $(0.49 \leq \mathrm{a} \leq 0.93)$. The CCI was substantially based upon the Coolidge Axis II Inventory (CATI; Coolidge \& Merwin, 1992), which has a long history of supportive clinical and nonclinical studies and excellent median test-retest reliability (one week) across its scales of $r=0.90$ (e.g., Coolidge \& Anderson, 2002; Coolidge, Davis, \& Segal, 2007; Coolidge \& Segal, 2007, 2009). The CCI scales in the present study are reported as T scores (except where noted) based on the current CATI 
normative sample (Coolidge, 2000). The CCI has recently been successfully used to differentiate between incarcerated male rapists $(n=251)$ and child molesters $(n=311$; Francia et al., 2010).

\section{RESULTS}

\section{Prevalence of ADHD and Its Subtypes as a Function of Gender}

Approximately $10.5 \%(n=416)$ of the inmates met categorical diagnostic criterion [answered with a 3 (more true than false) or a 4 (strongly true) on at least 12 of the 18 items on the ADHD scale] for ADHD of the total sample ( $n=3,962)$. Thus, the hypothesis that the prevalence of ADHD in adult inmates would be greater than the general population (2-5\%) was supported. Approximately $9.8 \%(n=337)$ of the male inmates met the criteria for ADHD, whereas $15.1 \%(n=79)$ of the female inmates met them. A 2_2 chi-squared test revealed that the female prevalence rate was greater than the male prevalence rate $\left[\chi^{2}(1, N=3962)=13.59, p<0.001\right]$, thus supporting the second hypothesis. There was, however, a small effect size (f2 $=0.003$ ). With regard to ADHD subtypes, $48 \%(n=198)$ of the ADHD inmates met the criteria for the hyperactive-impulsive subtype, $36 \%(n=150)$ met the criteria for the inattentive subtype, and $16 \%(n=68)$ met the criteria for the combined subtype. The latter finding was unexpected, as it was hypothesized, based on child and adolescent ADHD studies, that the inattentive subtype would be most common and the hyperactive- impulsive subtype would be least common. There was no difference in subtypes prevalence as a function of gender $\left[\chi^{2}(2, N=416)=5.03, p>0.05\right]$.

\section{Comorbidity}

One-way ANOVAs were used to compare the three ADHD subtype groups and a comparison group of inmates without ADHD for the following three Axis I scales on the CCI: generalized anxiety disorder, major depressive disorder, and schizophrenia; and the neuropsychological dysfunction scale and executive dysfunctions scale. The analyses yielded significant effects of group membership as well as large effect sizes (see Table 1). Tukey's post-hoc test indicated identical patterns for all analyses (also see Table 1). Specifically, the combined and inattentive groups, although not different from each other, had higher levels for all five scales than both the hyperactiveimpulsive group and comparison group of inmates without ADHD. In addition, the hyperactiveimpulsive group had higher levels than the comparison group of inmates without ADHD.

The three ADHD subtypes and comparison group of inmates without ADHD were also analyzed for mean differences across the 14 personality disorder scales of the CCI. All ANOVAs were statistically significant with large effect sizes (the histrionic scale had a moderate effect size; see Table 2). Tukey's tests revealed six different patterns of group differences. The most common pattern found (for the dependent, depressive, obsessive-compulsive, paranoid, passive-aggressive, and schizotypal scales) indicated that the combined and inattentive groups, although not different from each other, had higher levels than both the hyperactive-impulsive group and comparison group of inmates without ADHD; in addition, the hyperactive-impulsive group had higher levels compared with the comparison group of inmates without ADHD. 
Table 1. Descriptive and inferential statistics for Axis I Coolidge Correctional Inventory (CCI) scales, neuropsychological dysfunction scale, and the executive dysfunctions scale by ADHD subtype and comparison group

\begin{tabular}{|c|c|c|c|c|c|c|}
\hline \multirow{2}{*}{$\begin{array}{l}\text { Axis I clinical disorders } \\
\text { and neuropsychological } \\
\text { scales }\end{array}$} & \multicolumn{6}{|c|}{ T score means and standard deviations } \\
\hline & $\begin{array}{l}\text { ADHD: inattentive } \\
\text { group }\end{array}$ & $\begin{array}{c}\text { ADHD: hyperactive/ } \\
\text { impulsive group }\end{array}$ & $\begin{array}{l}\text { ADHD: combined } \\
\text { group }\end{array}$ & $\begin{array}{c}\begin{array}{c}\text { Comparison } \\
\text { group }\end{array} \\
\end{array}$ & $\mathrm{F}$ & $\eta^{2}$ \\
\hline Anxiety & $61.73(7.07)^{\mathrm{b}}$ & $56.51(6.56)^{c}$ & $62.45(6.45)^{\mathrm{b}}$ & $51.18(6.38)^{\mathrm{a}}$ & 129.19* & 0.3 \\
\hline Depression & $62.60(11.25)^{\mathrm{b}}$ & $54.01(9.51)^{c}$ & $63.17(9.28)^{b}$ & $47.31(8.63)^{\mathrm{a}}$ & $131.45^{*}$ & 0.3 \\
\hline Schizophrenia & $63.58(11.96)^{b}$ & $56.75(10.55)^{\mathrm{c}}$ & $66.8(10.96)^{b}$ & $46.51(10.08)^{\mathrm{a}}$ & $145.70 *$ & 0.3 \\
\hline \multicolumn{7}{|c|}{ Neuropsychological scales } \\
\hline $\begin{array}{l}\text { Neuropsychological } \\
\text { Dysfunction }\end{array}$ & $65.35(10.69)^{\mathrm{b}}$ & $52.11(9.55)^{c}$ & $65.14(11.66)^{b}$ & $45.39(8.99)^{\mathrm{a}}$ & $199.98 *$ & 0.4 \\
\hline Executive function deficits & $57.73(10.54)^{b}$ & $48.63(8.85)^{\mathrm{c}}$ & $58.12(9.21)^{\mathrm{b}}$ & $45.42(8.41)^{\mathrm{a}}$ & $91.41 *$ & $0.2^{\mathrm{t}}$ \\
\hline
\end{tabular}

Note. Degrees of freedom for all analyses were $d f_{1}=3, d f_{2}=823$; * $p<0.001$. $\eta^{2}$ (eta squared) $<0.06$, small; $\eta^{2} \geq 0.06$ to $\eta^{2}<0.14$, moderate; $\eta^{2} \geq 0.14$, large. Means with different superscripted letters were significantly different from one another, and superscripts in common indicate non-significant mean differences.

Table 2. Descriptive and inferential statistics for the Coolidge Correctional Inventory (CCI) personality disorder scales by ADHD subtype and comparison group

\begin{tabular}{|c|c|c|c|c|c|c|}
\hline \multirow[b]{2}{*}{$\begin{array}{c}\text { Axis II personality } \\
\text { disorder scales }\end{array}$} & \multicolumn{6}{|c|}{ T score means and standard deviations } \\
\hline & $\begin{array}{c}\text { ADHD: Inattentive } \\
\text { Group }\end{array}$ & $\begin{array}{l}\text { ADHD: Hyperactive/ } \\
\text { Impulsive Group }\end{array}$ & $\begin{array}{l}\text { ADHD: Combined } \\
\text { Group }\end{array}$ & Comparison & Group F & $\eta^{2}$ \\
\hline Antisocial & $61.23(10.97)^{\mathrm{b}}$ & $60.39(10.55)^{\mathrm{b}}$ & $64.92(11.08)^{\mathrm{c}}$ & $52.22(9.68)^{\mathrm{a}}$ & $58.99 *$ & 0.18 \\
\hline Avoidant & $60.69(10.95)^{b}$ & $50.23(9.48)^{\mathrm{a}}$ & $59.31(10.30)^{b}$ & $47.59(9.08)^{\mathrm{a}}$ & $83.96 *$ & 0.23 \\
\hline Borderline & $55.25(9.18)^{b}$ & $52.29(8.87)^{c}$ & $59.36(9.66)^{d}$ & $44.11(8.65)^{\mathrm{a}}$ & $105.65 *$ & 0.28 \\
\hline Dependent & $55.72(10.67)^{b}$ & $48.47(9.69)^{c}$ & $57.54(9.27)^{\mathrm{b}}$ & $43.49(8.44)^{\mathrm{a}}$ & $91.65^{*}$ & 0.25 \\
\hline Depressive & $59.28(12.79)^{\mathrm{b}}$ & $51.02(11.43)^{\mathrm{c}}$ & $62.17(10.98)^{b}$ & $44.12(10.95)^{\mathrm{a}}$ & $95.58 *$ & 0.26 \\
\hline Histrionic & $42.17(10.87)^{\mathrm{a}}$ & $47.89(10.86)^{b}$ & $48.27(11.24)^{b}$ & $39.42(9.18)^{a}$ & $39.02 *$ & 0.12 \\
\hline Narcissistic & $45.36(10.16)^{\mathrm{bc}}$ & $47.59(9.75)^{b}$ & $49.95(9.74)^{c}$ & $39.89(8.83)^{\mathrm{a}}$ & $45.55^{*}$ & 0.14 \\
\hline Obsessive-compulsive & $55.29(8.05)^{b}$ & $50.59(8.34)^{c}$ & $53.86(7.87)^{b}$ & $47.71(6.88)^{\mathrm{a}}$ & $43.09 *$ & 0.14 \\
\hline Paranoid & $61.85(12.95)^{\mathrm{b}}$ & $57.27(11.96)^{\mathrm{c}}$ & $63.78(11.14)^{\mathrm{b}}$ & $49.33(10.48)^{\mathrm{a}}$ & $68.08 *$ & 0.20 \\
\hline Passive-aggressive & $58.35(10.93)^{b}$ & $50.49(10.09)^{c}$ & $60.71(10.25)^{b}$ & $42.36(10.13)^{\mathrm{a}}$ & $129.17^{*}$ & 0.32 \\
\hline Schizotypal & $58.9(11.75)^{b}$ & $53.66(10.10)^{c}$ & $59.93(10.97)^{b}$ & $45.67(8.63)^{\mathrm{a}}$ & $96.39 *$ & 0.26 \\
\hline Schizoid & $66.22(11.11)^{\mathrm{b}}$ & $58.94(10.62)^{c}$ & $62.96(10.43)^{d}$ & $55.49(8.55)^{\mathrm{a}}$ & $49.04 *$ & 0.15 \\
\hline Sadistic & $54.66(12.35)^{\mathrm{b}}$ & $55.31(11.49)^{\mathrm{b}}$ & $60.24(13.69)^{\mathrm{c}}$ & $47.46(9.32)^{\mathrm{a}}$ & $46.02 *$ & 0.14 \\
\hline Self-Defeating & $63.19(9.07)^{\mathrm{b}}$ & $60.71(8.25)^{b}$ & $66.93(8.24)^{c}$ & $52.39(9.06)^{\mathrm{a}}$ & $101.70 *$ & 0.27 \\
\hline
\end{tabular}

Note. Degrees of freedom for all analyses were $d f_{1}=3, d f_{2}=823$; * $p<0.001$. $\eta^{2}$ (eta squared) $<0.06$, small; $\eta^{2} \geq 0.06$ to $\eta^{2}<0.14$, moderate; $\eta^{2} \geq 0.14$, large. Means with different superscripted letters were significantly different from one another, and superscripts in common indicate non-significant mean differences.

\section{DISCUSSION}

\section{Prevalence of ADHD}

The impetus for the present study was that few studies to date have examined ADHD according to the strict DSM criteria in adult inmates as a function of gender. When we adhered to the current DSM ADHD criteria, it was found that the overall prevalence rate (10.5\%) was substantially higher than the rate found in adults in the general population (2-5\%), but the elevated rate is generally consistent with previous studies of incarcerated juveniles and adults (e.g., Chae et al., 2001; Rösler et al., 2004; Teplin et al., 2002; Vreugdenhil et al., 2004). This apparently robust finding of a two to five times greater prevalence of ADHD in prison inmates than in the general population raises two concerns. First, because it is suspected that untreated ADHD might negatively impact treatment and rehabilitation programs, it may behoove prison administrators and their mental health professionals to assess and identify inmates upon admission for ADHD. Secondly, as previously noted, if half of clinic-referred children with ADHD have comorbid ODD or CD (as 
noted in DSM-IV-TR), then they are undoubtedly at risk for developing behaviors in adulthood that may lead them into conflicts with the legal system. Thus, it appears important not only to assess ADHD in childhood but also to assess comorbid psychopathologies (e.g., ODD or CD) that may have the potential to increase their risk of adult criminal behavior.

The finding that the ADHD rate among female prisoners (15.1\%) was higher than the rate among male prisoners $(9.8 \%)$ in the present sample stands in contrast with studies in the general population that show a 2:1 to 9:1 male:female ratio (DSMIV-TR). However, the present finding is consistent with research of incarcerated juveniles (Chae et al., 2001; Teplin et al., 2002), which consistently shows greater ADHD rates in female juveniles. There is the possibility that this greater rate of ADHD in these adult women is not necessarily unique to the nature of ADHD but may be characteristic of the more general finding that many kinds of psychopathology are more elevated in incarcerated women (e.g., Coolidge et al., 2009; Lewis et al., 1991; Teplin et al., 2002). One interpretation of this reverse-gender effect in prison inmates may be that since men of any age in the general population are more prone to ADHD than women, it may suggest that women are generally more invulnerable to ADHD, either genetically or constitutionally. Thus, when a woman does exhibit the symptoms of ADHD, it may be indicative of the symptoms and associated comorbid psychopathologies being more severe, as they must overcome a woman's greater invulnerability to ADHD than that of a man. Some of the reasons for the greater severity of a mental disorder for young women compared with young men have been discussed elsewhere (e.g., Cauffman, Lexcen, Goldweber, Shulman, \& Grisso, 2007; Eme, 1992). This finding certainly deserves further investigation and possibly suggests screening and treatment differentials for inmates based on gender.

Unexpectedly, the most prevalent subtype was the hyperactive-impulsive type, with the inattentive type being the second most prevalent, and the combined type being the least prevalent. Willcutt and colleagues (1999) found that hyperactive-impulsive symptoms were more strongly associated with both ODD and CD than inattention symptoms, so it is possible that the finding of a greater prevalence of the hyperactive-impulsive type in inmates may be a function of its comorbidity with ODD and CD. Millstein, Wilens, Biederman, and Spencer (1997) found that an overwhelming majority of adults with ADHD (93\%) were of the combined type (56\%) or the inattentive types (37\%). They found only 2\% of ADHD adults presented with the hyperactiveimpulsive type. Thus, it appears that the present findings of a much higher prevalence of the hyperactive-impulsive type (48\%) may highlight the importance of identifying ADHD's comorbid psychopathologies in childhood and adolescence. In addition, it is thought that hyperactiveimpulsive symptoms remit with age compared with inattentive symptoms, which may worsen with age (Hurtig et al., 2007). One possible explanation is that the present results may be due to the uniqueness of this prison population, that is, individuals with the hyperactive-impulsive type may be at greater risk of ending up in prison as a result of the comorbid behavioral presentation of the hyperactive-impulsive symptoms. It seems reasonable that hyperactive-impulsive behaviors such as fast driving, running red lights and stop signs, dangerous drug use, and impulsive gambling have a greater likelihood of resulting in criminal charges, compared with inattentive behaviors such as difficulty following directions or inattention to details.

\section{Comorbidity}

Overall, the combined and inattentive groups, although not different from each other, had higher levels for depression, anxiety, EF deficits, NPD, schizophrenia, psychotic thinking, and a significant number of the personality disorders (dependent, depressive, obsessive-compulsive, 
paranoid, passive-aggressive, and schizotypal) than both the hyperactive-impulsive group and comparison group. In addition, the hyperactive-impulsive group had higher levels than the comparison group. The higher rate of comorbidity for the ADHD group found in the current study is consistent with past findings (Barkley, 2005; DSM-IV-TR; Murphy \& Barkley, 1996; Pennington \& Ozonoff, 1996). The exact underpinnings as to why people with ADHD consistently display higher rates of comorbidity are unknown. However, given the abundance of research showing a strong genetic and neurobiological etiology of the disorder, it is likely that these same factors lead to the increased rate of comorbid disorders (e.g., Wilens, Biederman, \& Spencer, 2002). Regardless of the underpinnings, these results clearly demonstrate the need for correctional systems to screen their inmates for ADHD upon admission, as inmates with ADHD are at a much higher risk of presenting a wide range of psychopathologies. Early identification of inmates with ADHD followed by proper psychological/psychiatric treatment would possibly improve the success of rehabilitation programs for inmates and thereby help decrease recidivism rates (see Eme, 2009). This is an important empirical question that future research should target. Secondly, this pattern of greater comorbid psychopathology associated with the ADHD inattentive and combined subtypes rather than the hyperactive-impulsive subtype is interesting, and certainly warrants replication. Again, this finding strengthens the importance of initial admission screening for ADHD symptomatology among prisoners.

\section{Study Strengths and Limitations}

Major strengths of the present study included its large sample size, its adherence to strict DSM ADHD criteria, its examination of many forms of comorbid psychopathology, and the examination of ADHD prevalence rates as a function of gender. Several limitations of the present study should be mentioned. First, this study includes the use of a single self-reported measure of ADHD and a single self-report for all other scales. Whereas self-report measures are common in practice and research, future studies in this area would benefit from reports from significant others and the inclusion of structured or semi-structured interviews for diagnoses which, while timeconsuming, also lead to the most replicable and valid diagnoses (Segal, Mueller, \& Coolidge, 2012). Also, it is important to note that we have determined by operational definition that meeting the DSM-IV-TR diagnostic criterion for ADHD was synonymous with an official diagnostic classification; however, the authors recognize that the operational definition used in the present study is not actually synonymous with an official diagnostic classification. As we noted previously, future studies with reports from significant others and individual clinical interviews, particularly with regard to substantiating and validating the operational definition used in the present study, would be invaluable. A second limitation was the cross-sectional design of the study which presents only a snapshot of psychopathology one point in time. It would be interesting to explore changes in psychopathology over time in a longitudinal or prospective design.

\section{CONCLUSIONS}

The present results indicate that the prevalence rate of ADHD in adult prison inmates is substantially higher than that of the general population, and it appears to be higher in female inmates than male inmates. Furthermore, the most prevalent subtype was the hyperactiveimpulsive subtype, although there appears to be greater comorbid psychopathology associated with the inattentive and combined subtypes. As the presence of ADHD may impact the success of rehabilitation and educative programs with inmates, the careful assessment of ADHD and any 
comorbid psychopathology, including neuropsychological dysfunction, should be a priority in initial inmate screening and evaluation.

\section{REFERENCES}

American Psychiatric Association. (1987). Diagnostic and statistical manual of mental disorders ( ${ }^{\text {rd }}$ ed., revised). Washington, DC: Author.

American Psychiatric Association. (1994). Diagnostic and statistical manual of mental disorders (4 ${ }^{\text {th }}$ ed.). Washington, DC: Author.

American Psychiatric Association. (2000). Diagnostic and statistical manual of mental disorders (4 $4^{\text {th }}$ ed., text revision). Washington, DC: Author.

Barkley, R. A. (2005). Attention-deficit hyperactivity disorder: A handbook for diagnosis and treatment ( $3^{\text {rd }}$ ed.). New York: Guilford Press.

Barkley, R. A., \& Murphy, K. R. (1998). Attention-deficit hyperactivity disorder: A clinical workbook (2 ${ }^{\text {nd }}$ ed.). New York, NY: Guilford Press.

Barzman, D. H., Fieler, L., \& Sallee, F. R. (2004). Attention-deficit hyperactivity disorder diagnosis and treatment: Separating myth from substance. The Journal of Legal Medicine, 25, 23-38.

Cauffman, E., Lexcen, F., Goldweber, A., Shulman, E., \& Grisso, T. (2007). Gender differences in mental health symptoms among delinquent and community youth. Youth Violence and Juvenile Justice, 5, 287-307.

Chae, P. K., Jung, H., \& Noh, K. (2001). Attention deficit hyperactivity disorder in Korean juvenile delinquents. Adolescence, 36, 707-725.

Coolidge, F. L. (2000). Coolidge Axis II Inventory Manual. Colorado Springs, CO: Author.

Coolidge, F. L. (2004). Coolidge Correctional Inventory Manual. Colorado Springs, CO: Author.

Coolidge, F. L., \& Anderson, L. W. (2002). Personality profiles of women in multiple abusive relationships. Journal of Family Violence, 17, 117-131.

Coolidge, F. L., Davis, F. L., \& Segal, D. L. (2007). Understanding madmen: A DSM-IV assessment of Adolf Hitler. Individual Differences Research, 5, 30-43.

Coolidge, F. L., Marle, P. D., Van Horn, S. A., \& Segal, D. L. (2011). Clinical syndromes, personality disorders, and neurocognitive differences in male and female inmates. Behavioral Sciences \& the Law, 29, 741-751.

Coolidge, F. L., \& Merwin, M. M. (1992). Reliability and validity of the Coolidge Axis II Inventory: A new inventory for the assessment of personality disorders. Journal of Personality Assessment, 59, 223-238.

Coolidge, F. L., \& Segal, D. L. (2009). Is Kim Jong-il like Saddam Hussein and Adolf Hitler? A personality disorder evaluation. Behavioral Sciences of Terrorism and Political Aggression, 1, 195-202.

Coolidge, F. L., \& Segal, D. L. (2007). Is Saddam Hussein like Adolf Hitler? A personality disorder investigation. Military Psychology, 19, 1-11.

Coolidge, F. L., Segal, D. L., Klebe, K. J., Cahill, B. S., \& Whitcomb, J. M. (2009). Psychometric properties of the Coolidge Correctional Inventory in a sample of 3,962 prison inmates. Behavioral Sciences \& the Law, 27, 713-726.

Coolidge, F. L., Segal, D. L., Pointer, J. C., Knaus, E. A., Yamazaki, T. G., \& Silberman, C. S. (2000). Personality disorders in elderly inpatients with chronic mental illness. Journal of Clinical Geropsychology, 6, 63-72.

Eiraldi, R. B., Power, T. J., \& Nezu, C. M. (1997). Patterns of comorbidity associated with subtypes of attention-deficit/hyperactivity disorder among 6- to 12-year-old children. Journal of the American Academy of Child and Adolescent Psychiatry, 36, 503-514. 
Eme, R. F. (1992). Selective female affliction in the developmental disorders of childhood: A literature review. Journal of Clinical Child Psychology, 21, 354-365.

Eme, R. F. (2009). Attention-Deficit/Hyperactivity Disorder and correctional health care. Journal of Correctional Health Care, 15, 5-18.

Eyestone, L., \& Howell, R. (1994). An epidemiological study of ADHD and major depression in a male prison population. The Bulletin of the American Academy of Psychiatry and the Law, 22, 181-193.

Francia, A. A., Coolidge, F. L., White, L. A., Segal, D. L., Cahill, B. S., \& Estey, A. J. (2010). Personality disorder profiles in incarcerated male rapists and child molesters. American Journal of Forensic Psychology, 28, 1-14.

Graetz, B. W., Sawyer, M. G., Hazell, P. L., Arney, F., \& Baghurst, P. (2001). Validity of DSM-IV ADHD subtypes in a nationally representative sample of Australian children and adolescents. Journal of the American Academy of Child and Adolescent Psychiatry, 40, 1410-1417.

Hurley, P. J., \& Eme, R. (2008). ADHD and the criminal justice system: Spinning out of control. Charleston: BookSurge.

Hurtig, T., Ebeling, H., Taanila, A, Miettunen, J., Smalley, S. L., \& McGough, J. J. (2007). ADHD symptoms and subtypes: Relationship between childhood and adolescent symptoms. Journal of the American Academy of Child and Adolescent Psychiatry, 46, 1605-1613.

Lewis, D. O., Yeager, C. A., Cobham-Portorreal, C. S., Klein, N., Showater, C., \& Anthony, A. (1991). A follow-up of female delinquents: Maternal contributions to the perpetuation of deviance. Journal of the American Academy of Child and Adolescent Psychiatry, 30, 197-201.

McGough, J. J., \& Barkley, R. A. (2004). Diagnostic controversies in adult attention deficit hyperactivity disorder. The American Journal of Psychiatry, 161, 1948-1956.

Millstein, R., Wilens, T. E., Biederman, J., \& Spencer, T. J. (1997). Presenting ADHD symptoms and subtypes in clinically referred adults. Journal of Attention Disorders, 2, 159-166.

Murphy, K., \& Barkley, R. A. (1996). Attention deficit hyperactivity disorder in adults. Comprehensive Psychiatry, 37, 393-401.

Pennington, B. F., \& Ozonoff, S. (1996). Executive functions and developmental psychopathology. Journal of Child Psychology and Psychiatry, 37, 51-87.

Polanczyk, G., Silva de Lima, M., Horta, B. L., Biederman, J., \& Rohde, L. A. (2007). The worldwide prevalence of ADHD: A systematic review and meta-regression analysis. The American Journal of Psychiatry, 164, 942-948.

Retzlaff, P., Stoner, J., \& Kleinsasser, D. (2002). The use of the MCMI-III in the screening and triage of offenders. International Journal of Offender Therapy and Comparative Criminology, 46, 319-332.

Rösler, M., Retz, W., Retz-Junginger, P., Hengesch, G., Schneider, M., Supprian, T., et al. (2004). Prevalence of attention-deficit/hyperactivity disorder (ADHD) and comorbid disorders in young male prison inmates. European Archives of Psychiatry and Clinical Neuroscience, 254, 365-371.

Segal, D. L., Mueller, A., \& Coolidge, F. L. (2012). Structured and semi-structured interviews for differential diagnosis: Fundamentals, applications, and essential features. In M. Hersen \& D. C. Beidel (Eds.) Adult psychopathology and diagnosis (6 ${ }^{\text {th }}$ ed., pp. 91-115). New York: Wiley.

Span, S. A., Earleywine, M., \& Strybel, T. Z. (2002). Confirming the factor structure of attention deficit hyperactivity disorder symptoms in adult, nonclinical samples. Journal of Psychopathology and Behavioral Assessment, 24, 129-136.

Szatmari, P., Offord, D. R., \& Boyle, M. H. (1989). Correlates, associated impairments, and patterns of service utilization of children with attention deficit disorders: Findings from the Ontario Child Health Study. Journal of Child Psychology and Psychiatry, 30, 205-217. 
Teplin, L. A., Abram, K. M., McClelland, G. M., Dulcan, M. K., \& Mericle, A. A. (2002). Psychiatric disorders in youth in juvenile detention. Archives of General Psychiatry, 59, 1133-1143.

Vreugdenhil, C., Doreleijers, T. A. H., Vermeiren, R., Wouters, L. F. J. M., \& Van Den Brink, W. (2004). Psychiatric disorders in a representative sample of incarcerated boys in the Netherlands. Journal of the American Academy of Child and Adolescent Psychiatry, 43, 97-104.

Wasserstein, J. (2005). Diagnostic issues for adolescents and adults with ADHD. Journal of Clinical Psychology, 61, 535-547.

Wilens, T. E., Biederman, J., \& Spencer, T. J. (2002). Attention-deficit /hyperactivity disorder across the lifespan. Annual Medical Review, 53, 113-131.

Willcutt, E. G., Pennington, B. F., Chhabildas, N. A., Friedman, M. C., \& Alexander, J. (1999). Psychiatric comorbidity associated with DSM-IV ADHD in a non-referred sample of twins. Journal of the American Academy of Child and Adolescent Psychiatry, 38, 1355-1362.

Wolraich, M., Hannah, J., Pinnock, T., Baumgaertel, A., \& Brown, J. (1996). Comparison of diagnostic criteria for attention-deficit hyperactivity disorder in a county-wide sample. Journal of the American Academy of Child and Adolescent Psychiatry, 35, 319-324. 